\title{
COMPARISON OF MODULE PERFORMANCE CHARACTERIZATION METHODS
}

\author{
B. Kroposki and W. Marion \\ National Renewable Energy Laboratory, Golden, CO, 80401 \\ D. L. King, W. E. Boyson, and J. A. Kratochvil \\ Sandia National Laboratories, Albuquerque, NM, 87185
}

\begin{abstract}
The rating and modeling of photovoltaic (PV) module performance has been of concern to manufacturers and system designers for over 20 years. Both the National Renewable Energy Laboratory (NREL) and Sandia National Laboratories (SNL) have developed methodologies to predict module and array performance under actual operating conditions. This paper compares the two methods of determining the performance of PV modules. The methods translate module performance to actual or reference conditions using slightly different approaches. The accuracy of both methods is compared for both hourly, daily, and annual energy production over a year of data recorded at NREL in Golden, CO. The comparison of the two methods will be presented for five different PV module technologies.
\end{abstract}

\section{INTRODUCTION}

In the early 1990s, researchers at both the National Renewable Energy Laboratory (NREL) and Sandia National Laboratories (SNL) started developing methodologies to predict module and array performance under actual operating conditions. In 1994, NREL conducted research to determine how well module energy rating techniques of that time predicted power output. From this research, NREL initiated an effort to develop a consensus-based approach to rating photovoltaic modules, based on results of previous energy ratings research. This new approach was intended to complement the de facto standard for module power rating at Standard Reporting Conditions [1]. Using technical input from a number of sources and under the guidance of an industry-based Technical Review Committee, an approach was developed to predict module performance and to determine a module energy rating [2].

A module energy rating (MER) was developed that consists of 10 estimates of the energy produced by a module in one day: one estimate for each of five different weather/location combinations. The five weather and location combinations are representative of the range of environmental conditions anticipated for typical uses of PV modules in the contiguous United States. The final locations were chosen based on criteria developed by the Technical Review Committee for describing the following day types: Hot Sunny, Hot Cloudy, Cold Sunny, Cold
Cloudy, and Nice (Cool Sunny). To correctly rate a PV module at the five weather conditions, an accurate way to model PV module performance under all operating conditions was needed. NREL has developed and validated one such method [3]. The NREL method characterizes the module performance under laboratory conditions and uses several established analytical models to translate this performance matrix fo outdoor conditions using irradiance, air temperature, and spectral response of the module.

In 1991, Sandia initiated an effort to develop improved outdoor performance measurement methods and a performance model for modules and arrays, with the goal of improving the performance models used for PV system design. The resulting methods were first applied in the field at the array level in 1995 [4]. The Sandia methods have continued to evolve based on extensive outdoor module testing, now providing a method for predicting module output under any operating condition [5]. The Sandia method compensates for the influences of irradiance, temperature, air mass, and angle-of-incidence on module performance. Parameters required for module performance modeling are determined directly using specific outdoor test procedures, with the module mounted on a two-axis solar tracker during a period of one or more days. Sandia's performance model was designed to be applicable to all module technologies, including thin-film and concentrators.

This paper compares the two methods of determining the performance of PV modules. The methods translate module performance characterized in a laboratory to actual or reference conditions using slightly different approaches. The accuracy of both methods is compared for both hourly and daily energy production over a year of data recorded at NREL in Golden, CO. The comparison of the two methods will be presented for five different PV module technologies: multicrystalline silicon (mc-Si), dualjunction amorphous silicon (a-Si/a-Si:Ge), triple-junction amorphous silicon (a-Si/a-Si/a-Si:Ge), cadmium telluride (CdTe), and copper indium diselenide (CIGSS).

\section{NREL METHOD}

The method developed at NREL is fully described in the reference [3]. This method characterizes the PV module performance under laboratory conditions, and then 


\section{DISCLAIMER}

This report was prepared as an account of work sponsored by an agency of the United States Government. Neither the United States Government nor any agency thereof, nor any of their employees, make any warranty, express or implied, or assumes any legal liability or responsibility for the accuracy, completeness, or usefulness of any information, apparatus, product, or process disclosed, or represents that its use would not infringe privately owned rights. Reference herein to any specific commercial product, process, or service by trade name, trademark, manufacturer, or otherwise does not necessarily constitute or imply its endorsement, recommendation, or favoring by the United States Government or any agency thereof. The views and opinions of authors expressed herein do not necessarily state or reflect those of the United States Government or any agency thereof. 


\section{DISCLAIMER}

Portions of this document may be illegible in electronic image products. Images are produced from the best available original document. 
uses translation procedures to estimate performance for the outdoor conditions. Three technical areas address implementing the NREL method: (1) determining PV module temperature and irradiance correction factors and functions, (2) determining the irradiance and PV module temperature for the desired time and location, and (3) translating a reference current-voltage (I-V) curve to the irradiance and PV module temperature conditions.

Based on Annex A2 of ASTM E1036-96 [1], with modifications, the PV module temperature and irradiance correction factors and functions are determined from a matrix of short-circuit current $\left(\mathrm{I}_{\mathrm{sc}}\right)$ and open-circuit voltage $N_{o c}$ ) values resulting from I-V curve measurements over a range of six irradiances $\left(150-1000 \mathrm{~W} / \mathrm{m}^{2}\right)$ and six operating temperatures $\left(5^{\circ}-60^{\circ} \mathrm{C}\right)$. Three correction factors and functions are determined: $\alpha$, the Isc correction factor for temperature; $\beta(E)$, the Voc correction for temperature as a function of irradiance, $E$; and $\delta(T)$, the Voc correction for irradiance as a function of the PV module temperature, $T$. Hourly average solar radiation and meteorological data are used to model values of incident irradiance and PV module temperature for a desired hour. The effective irradiance, $E$, is determined by:

$$
E=\frac{\int_{d}^{b} E_{I N C}(\lambda) S R(\lambda) d \lambda}{\int_{d}^{b} E_{R E F}(\lambda) S R(\lambda) d \lambda} \cdot 1000 \mathrm{~W} / \mathrm{m}^{2},
$$

where:

$\lambda=$ wavelength

$E_{I N C}(\lambda)=$ incident spectral irradiance

$E_{R E F}(\lambda)=A M 1.5$ spectral irradiance at $1000 \mathrm{~W} / \mathrm{m}^{2}[6]$

$S R(\lambda)=$ module spectral response (AW) per [7]

$\mathrm{a}, \mathrm{b}=$ integration limits

For series-connected multijunction modules, the spectral response of the junction that gives the smallest numerator (current at actual conditions) is used to evaluate the numerator, and the spectral response of the junction that gives the smallest denominator (current at reference conditions) is used to evaluate the denominator. Spectral responses for two junctions are required to evaluate equation 1 if one junction is the current-limiting factor at reference conditions and the other junction is the current-limiting factor at actual conditions. The model SEDES2 [8] is used to calculate the incident spectral irradiance.

A model developed by Fuentes [9] for use in the simulation program PVFORM is used to determine module temperature from the air temperature, wind speed, solar irradiance, and the module's NOCT (nominal operating cell temperature).

Using the effective irradiance and the PV module temperature, Isc and $\mathrm{Voc}$ are calculated and a reference $\mathrm{I}-\mathrm{V}$ curve from a family of measured curves is translated to determine maximum power. These procedures are based on modifications to ASTM E103696 and use equations 2 and 3 for Isc and Voc. In equations 2 and 3 , the zero subscripts denote ASTM Standard Reporting Conditions (SRC).

$$
\begin{aligned}
& I s c=\frac{E}{E_{0}} \cdot I s c_{0} \cdot\left[1+\alpha \cdot\left(T-T_{0}\right)\right] \\
& V o c=V o c_{0} \cdot\left[1+\beta_{0}(E) \cdot\left(T-T_{0}\right)\right] \cdot\left[1+\delta(T) \cdot \ln \left(E / E_{0}\right)\right] \cdot
\end{aligned}
$$

In order to determine the I-V curve for desired conditions, a "reference" I-V curve is selected for translation from the family of $\mathrm{IV}$ curves measured to determine the correction factors and functions. The I-V curve selected for the reference is the curve measured under the conditions of irradiance and temperature closest to those desired. This selection process minimizes errors caused by the I-V curve translation not accounting for changes in fill factor as temperature and irradiance change. Each $(I, V)$ data pair of the reference I-V curve is then translated to the desired conditions using equations 4 and 5. The subscript $R$ refers to the reference I-V curve, and $I_{s c}$ and $V_{o c}$ are determined with equations 2 and 3 .

$$
\begin{aligned}
& I=I_{R} \cdot \frac{I s c}{I s c_{R}} \\
& V=V_{R} \cdot \frac{V o c}{V o c_{R}} .
\end{aligned}
$$

Because the translation procedure does not alter the fill factor, the reference I-V curve data pair for maximum power becomes the translated I-V curve data pair for maximum power. To determine the current at a specified voltage, the current may be interpolated using the two adjacent I-V curve data pairs from the translated I-V curve with voltages above and below the specified voltage.

\section{SANDIA METHOD}

The Sandia performance model and related outdoor test procedures are described in reference [5]. Only minor modifications to the performance model have been made since this publication appeared in 1998 . The original goals in developing the Sandia method were the following: (1) test procedures and performance model would be applicable to all PV technologies at both the module and array level, (2) all required performance parameters could be determined experimentally using outdoor test procedures, and (3) the accuracy of the performance model would clearly meet the needs of PV system designers. The first two goals have been achieved, and work such as documented in this paper will help determine if the third goal has been achieved.

Basically, three separate outdoor test procedures are performed by Sandia to obtain the required module parameters used in the performance model. Tests are performed with the module mounted on a two-axis solar tracker. Typically, I-V measurements are recorded over a day-long period of time with at least half of the day (morning or afternoon) exhibiting clear-sky conditions. The measurements during clear-sky conditions provide performance parameters at the ASTM Standard Reporting Conditions, as well as an empirical relationship quantifying the influence of solar spectral variation on short-circuit 
current. The measurements recorded during overcast or cloudy conditions provide parameters that describe module voltage at low irradiance levels. A shade/unshade procedure is used to measure separate temperature coefficients for short-circuit current $\left(I_{s c}\right)$, maximum-power current $\left(I_{\mathrm{mp}}\right)$, open-circuit voltage $\left(\mathrm{V}_{\mathrm{oc}}\right)$, and maximumpower voltage $\left(V_{m p}\right)$. The third test procedure involves moving the solar tracker through a programmed sequence of offset angles to quantify the influence on $I_{s c}$ of the angle-of-incidence of the beam component of irradiance. Separately quantifying the spectral, angle-of-incidence, and thermal influences makes it possible to linearize most of the elements of the performance model, while at the same time maintaining equations in the model that are consistent with solar cell physics. The set of equations used in the Sandia performance model is given below.

$$
\begin{aligned}
& I_{s c}=I_{s c o} \cdot f_{1}\left(A M_{a}\right) \cdot\left\{\left(E_{b} \cdot f_{2}(A O I)+f_{d} \cdot E_{d i f f}\right) / E_{o}\right\} \cdot\left\{1+\alpha_{i s c} \cdot\left(T_{c}-T_{0}\right)\right\} \\
& E_{\theta}=I_{s c} /\left[I_{s c o} \cdot\left\{1+\alpha_{l s c} \cdot\left(T_{c}-T_{0}\right)\right\}\right] \\
& I_{m p}=I_{m p o} \cdot\left\{C_{0} \cdot E_{e}+C_{1} \cdot E_{e}^{2}\right\} \cdot\left\{1+\alpha_{l m p} \cdot\left(T_{c}-T_{0}\right)\right\} \\
& \delta\left(T_{c}\right)=n \cdot k \cdot\left(T_{c}+273.15\right) / q \\
& V_{o c}=V_{o c o}+N_{s} \cdot \delta\left(T_{c}\right) \cdot \ln \left(E_{\theta}\right)+\beta_{\text {voc }}\left(E_{\theta}\right) \cdot\left(T_{c}-T_{0}\right) \\
& V_{m p}=V_{m p o}+C_{2} \cdot N_{s} \cdot \delta\left(T_{c}\right) \cdot \ln \left(E_{\theta}\right)+C_{3} \cdot N_{s} \cdot\left\{\delta\left(T_{c}\right) \cdot \ln \left(E_{e}\right)\right\}^{2}+ \\
& P_{m p}=I_{m p} \cdot V_{m p} \\
& \beta_{V m p}\left(E_{\theta}\right) \cdot\left(T_{c}-T_{0}\right)
\end{aligned}
$$

Where:

$I_{s c}=$ Module short-circuit current, (A)

$I_{m p}=$ Current at maximum-power point, $(A)$

$V_{o c}=$ Open-circuit voltage, $(M)$

$V_{m p}=$ Voltage at maximum-power point, $(V)$

$P_{m p}=$ Power at maximum-power point, $(W)$

$E_{b}=E_{\text {dni }} \cos (A O I)$, beam irradiance, $\left(W / m^{2}\right)$

$E_{\text {diff }}=$ Diffuse irradiance, $\left(\mathrm{W} / \mathrm{m}^{2}\right)$

$\mathrm{f}_{\mathrm{d}}=$ Fraction of diffuse irradiance used by module

$E_{\theta}=$ "Effective" irradiance, dimensionless, or "suns"

$E_{0}=$ Reference irradiance, $1000 \mathrm{~W} / \mathrm{m}^{2}$

$\mathrm{AM}_{\mathrm{a}}=$ Absolute air mass, dimensionless, calculated from

sun elevation angle and site altitude

$\mathrm{AOI}=$ Solar angle-of-incidence, angle between normal

and beam component of sunlight, degrees

$T_{c}=$ Temperature of cells inside module, $\left({ }^{\circ} \mathrm{C}\right)$

$\mathrm{T}_{\mathrm{o}}=$ Reference temperature for performance model, $\left({ }^{\circ} \mathrm{C}\right)$

$f_{1}\left(A M_{a}\right)=$ Empirically determined polynomial relating

spectral influence on $I_{s c}$ to air mass

$f_{2}(A O I)=$ Empirically determined polynomial describing

AOl influence on $I_{s c}$

$I_{s c o}=I_{s c}\left(E=1000 \mathrm{~W} / \mathrm{m}^{2}, A M_{a}=1.5, T_{c}=25^{\circ} \mathrm{C}, A O I=0^{\circ}\right),(A)$

$I_{m p o}=I_{m p}\left(E_{\theta}=1, T_{c}=T_{0}\right),(A)$

$V_{\text {oco }}=V_{o c}\left(E_{e}=1, T_{c}=T_{0}\right),(M)$

$V_{\text {mpo }}=V_{\text {mp }}\left(E_{\theta}=1, T_{c}=T_{0}\right),(V)$

$\alpha_{\text {Isc }}=$ Normalized temperature coefficient for $l_{s c}\left(1 /{ }^{\circ} \mathrm{C}\right)$

$\alpha_{\text {Imp }}=$ Normalized temperature coefficient for $I_{m p},\left(1 /{ }^{\circ} \mathrm{C}\right)$

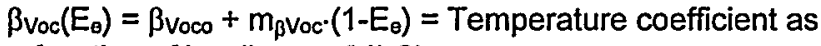
a function of irradiance, $\left(V /{ }^{\circ} \mathrm{C}\right)$

$\beta_{\text {Voco }}=$ Temp. coefficient for $V_{o c}$ at $1000 \mathrm{~W} / \mathrm{m}^{2},\left(\mathrm{~V} /{ }^{\circ} \mathrm{C}\right)$

$m_{\beta} V_{o c}=$ Coefficient providing irradiance dependence for

temperature coefficient, $\left(V /{ }^{\circ} \mathrm{C}\right)$

$\beta_{V m p}\left(E_{\theta}\right)=\beta_{V m p o}+m_{\beta V_{m p}}\left(1-E_{\theta}\right)=$ Temperature coefficient

as a function of irradiance, $\left(V^{\circ} \mathrm{C}\right)$

$\beta_{\text {Voco }}=$ Temp. coefficient for $V_{m p}$ at $1000 \mathrm{~W} / \mathrm{m}^{2},\left(\mathrm{~V} /{ }^{\circ} \mathrm{C}\right)$ $m_{\beta} V_{m p}=$ Coefficient providing irradiance dependence for temperature coefficient, $\left(\mathrm{V} /{ }^{\circ} \mathrm{C}\right)$

$\mathrm{C}_{\mathrm{i}}=$ Empirically-determined coefficients from outdoor tests

$\mathrm{n}=$ Empirically-determined diode factor for each cell in

module (dimensionless)

$\mathrm{N}_{\mathrm{s}}=$ Number of cells in series in a cell-string

$\mathrm{k}=$ Boltzmann's constant, 1.38066E-23, (J/K)

$q=$ Elementary charge, $1.60218 \mathrm{E}-19$, (coulomb)

$\delta\left(T_{c}\right) \cdot=\left(n \cdot k \cdot T_{c}\right) / q$, "thermal voltage" per cell, $T_{c}$ in Kelvin.

\section{VALIDATION DATA}

The data used for this validation study were taken for the entire calendar year of 1998 . The PV modules were part of a group located on the lower roof of NREL's Outdoor Test Facility (OTF). The group of modules was associated with an effort at NREL called the Performance and Energy Ratings Testbed (PERT). The PV modules faced south $\pm 2^{\circ}$ with a tilt from horizontal of $40^{\circ} \pm 1^{\circ}$. The tilt angle corresponds approximately to the latitude for the OTF site, whose coordinates are more precisely $39.74^{\circ}$ North latitude and $105.18^{\circ}$ West longitude. The data acquisition systems associated with the PERT recorded hourly or half-hourly values of module maximum power, as well as values for module back-surface temperatures, wind speed, and plane-of-array (POA) irradiance. In addition, solar radiation and meteorological data were also recorded at two other sites: the RMIS weather station and the Solar Radiation Research Laboratory (SRRL). The RMIS weather station is adjacent to the OTF building, and the SRRL weather station is on top of the mesa north of the OTF. Modules associated with the PERT were not manually cleaned, so natural soiling and cleaning (rain or snow) introduced uncontrolled variations in the measured data set.

Due to inherent differences in the NREL and Sandia performance models, there were also a few differences in the way that measured data were used in the models. The NREL method uses modeled values for POA irradiance, and the measured inputs for this model came from either the RMIS or SRRL. Similarly, the NREL method uses a model to determine module operating temperature based on irradiance, wind speed, and ambient temperature. For the NREL analysis, RMIS data were used unless faulty, in which case SRRL data were used. For the data analysis, the solar radiation, meteorological, and PV module data were checked for out-of-range and missing values to eliminate hours with clearly erroneous data.

The Sandia method used measured values for the POA irradiance indicated by the PERT instruments located adjacent to the modules, as well as directly measured module temperatures. In addition, the modules used in the analysis have not been characterized outdoors using Sandia's test procedures. Rather, the family of I-V curves measured in the lab at NREL was analyzed to obtain parameters required in the Sandia performance model. The effect of using procedures designed for analyzing outdoor performance measurements to analyze data obtained using a solar simulator could not be quantified. The empirical relationships Sandia used to account for 
solar spectral influence and for solar AOI were obtained from measurements made at Sandia on modules similar to those at the PERT.

\section{RESULTS}

Modeled and measured energy was compared on an hourly, daily, and annual basis. Using hourly input data from the PERT, RMIS, and/or SRRL data sets, the NREL and Sandia methods calculated hourly PV module energy and summed the hourly values to determine daily PV module energy. Suitability of the NREL and Sandia methods were evaluated by calculating the differences between modeled and measured energy. Figures 1 and 2 show representative samples of the difference between modeled and measured data for two module types versus date and incident irradiance.

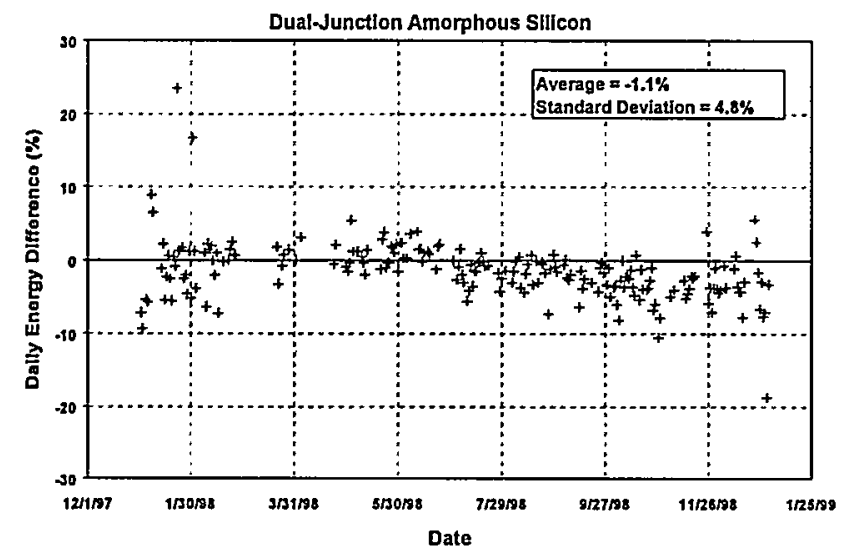

Fig. 1. NREL model. between modeled and measured daily energy vs. date for dual-junction a-Si.

Tables 1 and 2 summarize the differences in daily, hourly, and annual energy production between measured and modeled data using the NREL and Sandia methods. To further evaluate the performance models over a wide range of climatic conditions, modeled and measured values were compared for individual days selected to represent the five MER days. The days selected, and the MER day they represent, were $1 / 23 / 98$ (cold-sunny), $11 / 25 / 98$ (cold-cloudy), 4/24/98 (nice), 8/25/98 (hotcloudy), and 9/4/98 (hot-sunny). Figures 3 and 4 illustrate comparisons for two modules on two different days. The daily difference for the Hot-Sunny day, Figure 3, for the multicrystalline module for both models was less than $1 \%$. In this case, the measured daily energy produced by the mc-Si module was $328 \mathrm{Wh}$. The results for the triplejunction a-Si module, Figure 4, were not as good, about $12 \%$ and $9 \%$ difference for the NREL and SNL models respectively. However, this difference has relatively little influence on an annual energy basis because cloudy days contribute less to energy production. The measured daily energy for this Hot-Cloudy day was 102 Wh. Table 3 summarizes the percent differences between modeled and measured daily energy for both performance models and for all five days selected.

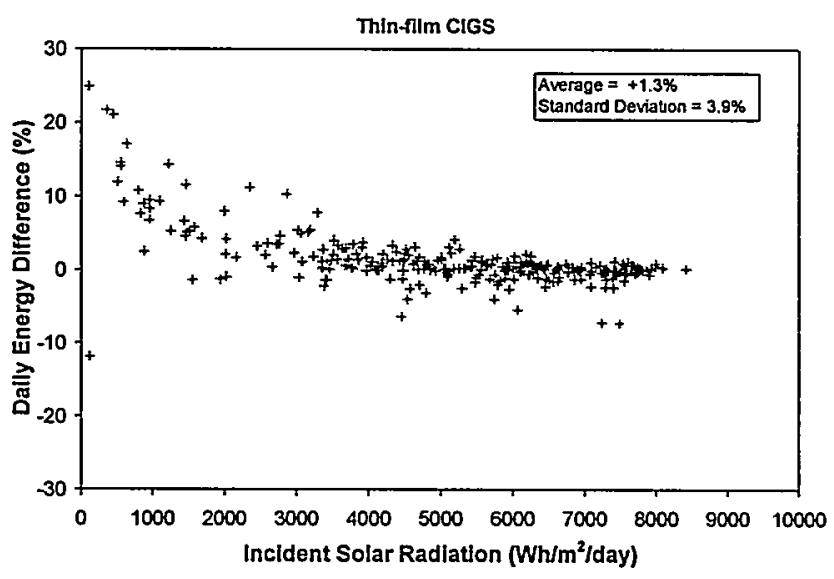

Fig. 2. SNL model. Difference in measured and calculated daily energy vs. solar radiation level, for thinfilm CIGS module.

Table 1. NREL Method. Differences in daily, hourly, and annual energy production, modeled vs. measured.

\begin{tabular}{|l|c|c|c|c|c|}
\hline \multicolumn{2}{|c|}{ NREL Modeling Results } & \multicolumn{1}{l|}{ Hourly } & \\
\hline & Daily & Annual \\
\hline & Avg. & Std. D. & Avg. & Std. D. & Avg. \\
\hline Module & $(\%)$ & $(\%)$ & $(\%)$ & $(\%)$ & $(\%)$ \\
\hline 3J-aSi & -6.0 & 3.9 & -9.6 & 18.8 & 4.7 \\
\hline CIGSS & -0.6 & 3.1 & 0.7 & 18.2 & -0.7 \\
\hline mc-Si & -0.3 & 2.9 & 0.5 & 34.3 & -0.1 \\
\hline 2J-aSi & -1.1 & 4.8 & 8 & 42.3 & -1.0 \\
\hline CdTe & 2.2 & 4.0 & 16.3 & 57.5 & 2.0 \\
\hline
\end{tabular}

Table 2. Sandia Method. Differences in daily, hourly, and annual energy production, modeled vs. measured.

\begin{tabular}{|c|c|c|c|c|c|}
\hline \multicolumn{4}{|c|}{ Sandia Modeling Results } & & \multirow[b]{2}{*}{ Annual } \\
\hline & Daily & & Hourly & & \\
\hline & Avg. & Std. D. & Avg. & Std. D. & Avg. \\
\hline Module & (\%) & $(\%)$ & $(\%)$ & (\%) & $(\%)$ \\
\hline $3 \mathrm{~J}-\mathrm{aSi}$ & -0.8 & 4.6 & -6.8 & 19.1 & -0.03 \\
\hline CIGSS & 1.3 & 3.9 & 5.5 & 13.9 & 0.4 \\
\hline mc-si & 1.7 & 2.9 & 3.1 & 9.9 & 1.4 \\
\hline $2 \mathrm{~J}-\mathrm{aSi}$ & 0.4 & 4.4 & -0.6 & 11.5 & 0.1 \\
\hline CdTe & 2.3 & 3.1 & 5.9 & 11.4 & 2.1 \\
\hline
\end{tabular}

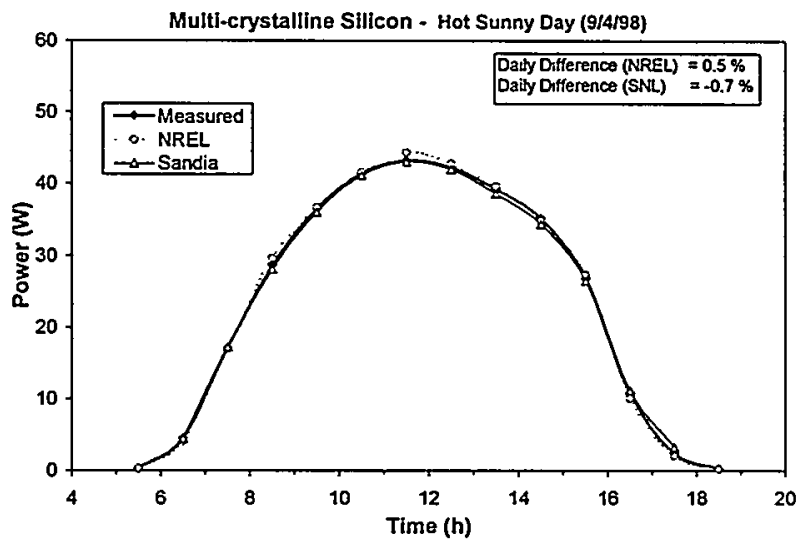

Fig. 3. Modeled vs. measured power on a hot sunny day for multicrystalline Si module. 


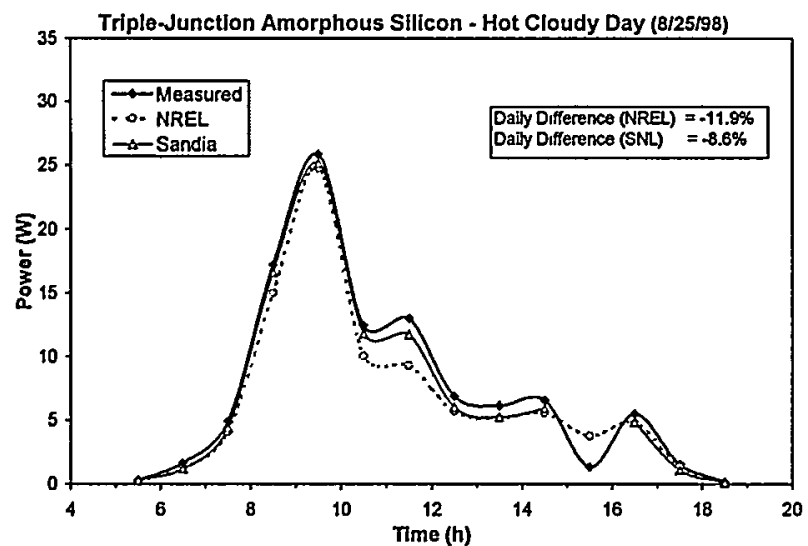

Fig. 4. Modeled vs. measured power on a hot cloudy day for triple-junction amorphous Si module.

Table 3. Differences (\%) between calculated and measured daily energy for both models on 5 selected days.

\begin{tabular}{|c|c|c|c|c|c|c|}
\hline & & mc-Si & $2 \mathrm{~J}-\mathrm{aSi}$ & $3 \mathrm{~J}-\mathrm{aSi}$ & CdTe & CIGSS \\
\hline Cold & NREL & 1.0 & 1.3 & 1.4 & -0.3 & -1.3 \\
\hline Sunny & $\overline{\text { SNL }}$ & 5.3 & 4.7 & 4.9 & 3.0 & -1.0 \\
\hline Cold & NREL & -3.0 & 3.9 & -8.3 & 2.6 & -0.3 \\
\hline Cloudy & SNL & $\overline{6.2}$ & 1.1 & -9.6 & 5.9 & 5.1 \\
\hline Nice & NREL & 1.0 & 2.1 & -2.9 & 2.1 & -0.1 \\
\hline & SNL & 2.5 & 5.0 & 4.7 & 1.3 & 0.7 \\
\hline Hot & NREL & -4.5 & -7.3 & -11.9 & 2.3 & $\overline{-3.8}$ \\
\hline Cloudy & SNL & -2.8 & -6.7 & -8.6 & -0.1 & -1.1 \\
\hline$\overline{\text { Hot }}$ & NREL & 0.5 & 0.1 & -7.3 & 3.1 & $\overline{0.5}$ \\
\hline Sunny & SNL & -0.7 & -0.8 & -2.3 & -0.2 & 0.2 \\
\hline
\end{tabular}

The NREL and Sandia models now provide defensible methods for calculating energy production from PV modules using either measured environmental parameters or tabulated typical meteorological year (TMY) data. The uncertainty in these calculated values is on the order of $\pm 10 \%$. Figure 5 illustrates calculated average daily energy values using both models compared to measured values. The bimodal shape evident in the figure directly correlates with the solar resource behavior for a module deployed in a fixed position at latitude tilt that occurs at the equinoxes.

\section{CONCLUSIONS}

Overall, the NREL and Sandia models show the ability to closely match the measured data values for hourly, daily and annual conditions and variability produced by environmental factors. More analysis will be required to better understand all of the results and implications evident in our collaborative investigation. Finding the most practical and beneficial ways to implement the test procedures and performance models investigated will also be an ongoing effort. The complete results of this study will be published in a more comprehensive NREL technical report.

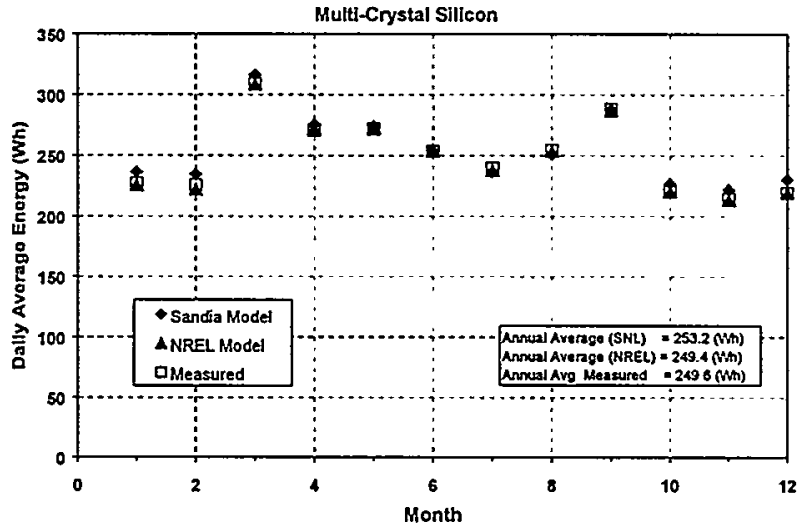

Fig. 5. Calculated and measured average daily energy by month for mc-Si module.

\section{ACKNOWLEDGEMENTS}

The authors would like to thank Keith Emery, Steve Rummel, Allan Anderberg, and Joe del Cueto for providing data measurements. The contributions of all participants in the MER Technical Review Committee are gratefully acknowledged. This work was supported under DOE contracts DE-AC36-99G010337 (NREL) and DE-AC0494AL85000 (Sandia).

\section{REFERENCES}

[1] ASTM E 1036-96, Standard Test Methods for Electrical Performance of Nonconcentrator Terrestrial Photovoltaic Modules and Arrays Using Reference Cells.

[2] B. Kroposki, D. Myers, K. Emery, L. Mrig, C. Whitaker, and J. Newmiller, "Photovoltaic Module Energy Ratings Methodology Development," $25^{\text {th }}$ IEEE PVSC, Washington, DC, 1996.

[3] B. Marion, B. Kroposki, K. Emery, J. del Cueto, D. Myers, and C. Osterwald, "Validation of a Photovoltaic Module Energy Ratings Procedure at NREL," NRELTP. 520-26909, 1999.

[4] D. L. King and P. E. Eckert, "Characterizing (Rating) Performance of Large Photovoltaic Arrays for All Operating Conditions, ${ }^{\text {, }} 25^{\text {th }}$ IEEE PVSC, 1996.

[5] D. King, J. Kratochvil, W. Boyson, and W. Bower, "Field Experience with a New Performance Characterization Procedure for Photovoltaic Arrays," $2^{\text {nd }}$ WCSEC, 1998.

[6] ASTM E 892-92, Standard Tables for Solar Spectral Irradiance at Air Mass 1.5 for a $37^{\circ}$ Tilted Surface.

[7] ASTM E 1021-95, Standard Test Methods for Measuring the Spectral Response of Photovoltaic Cells.

[8] S. Nann and K. Emery, "Spectral Effects on PV-Device Rating." Solar Energy Materials and Solar Cells, 27, pp. 189-216, 1992.

[9] M. K. Fuentes, A Simplified Thermal Model for FlatPlate Photovoltaic Arrays, SAND85-0330, Sandia National Laboratories Report, 1985. 